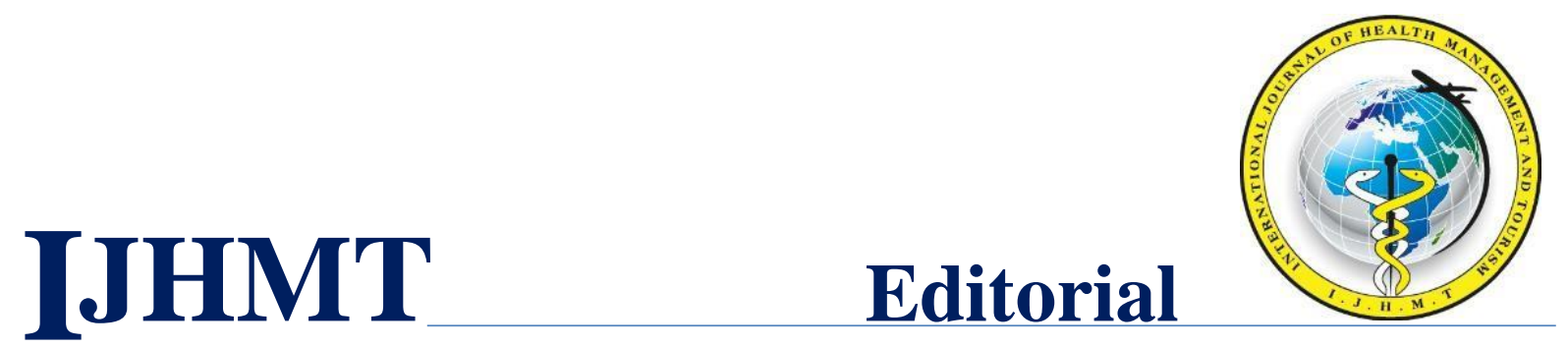

Internatıonal Journal Of Health Management And Tourism

\title{
EMOTIONAL AND CULTURAL INTELLIGENCE IN INTERNATIONAL PATIENT SERVICES: A COMPARATIVE STUDY OF PRIVATE HOSPITALS
}

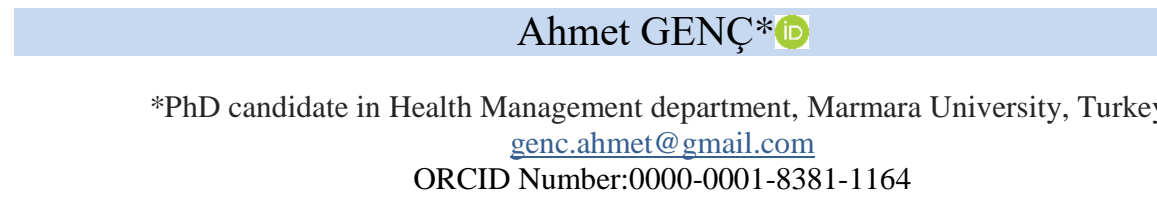

Received: 17.03 .2020

Accepted: 27.04 .2020

Research Article

Abstract: This study investigates difference among private hospitals in terms of emotional intelligence and cultural intelligences of their employees who are dealing with international patients. Because of the importance of satisfactory results from international patient services, and the best practices in healthcare services, understanding the effects of emotional intelligence and cultural intelligence of hospital employees are crucial. In this cross-sectional study, data was collected from 551 participants from seven private hospitals having at least 150-bed capacity in Istanbul and Gebze region of Turkey. The findings revealed that there was moderately significant difference among private hospitals in terms of "regulation of emotions" dimension at $p=0.024(p<0.05)$ level. Overall, this study is unique in regards to highlighting some differences among private hospitals in terms of emotional intelligence and cultural intelligence in their services towards international patients.

Keywords: Emotional intelligence, cultural intelligence, international patient services, healthcare services 


\section{Introduction}

In today's globalized world, diversity among patient populations as well as healthcare workforce have been increased (Dreachslin et. al.; 2000; Piacentini et. al., 2019; Seeleman et. al., 2015). Medical tourists, who are mostly travelling from rich countries, expatriates, and crossborder "transnational healthcare" were some of the contributing factors in the trends of more diverse patient population (Connell, 2006; Liu \& Chen, 2013; Mainil et. al, 2010; Mainil, 2012; Ormand, 2015).

Number of people who are traveling to different countries for health reasons has been increasing because of the quality and availability of care which is offered in affordable prices abroad (Connell, 2013). Other than that, international patients make their decisions about "destination hospitals" based on accessibility, credentials and experience of physicians, advertising and opinions of previous patients posted in social media (Kleefield, 2016). However, as the treatment process of a patient by itself has a complex and dynamic structure, treatment procedures of international patients may get more complicated due to communication barriers, "culturalism", "emotionally charged caregivers", "otherness", and stereotyping (Aronson et. al., 2013; Casey et. al., 2013; Kingsbury et. al., 2012; Lipsitz, 2012; Mainil, 2012; Priebe et. al., 2011; Taylor, 2005).

Going abroad for health reasons is not a simple travel but it appears to cause a "profound impact" on emotional status of patients and their relatives (Casey et. al., 2013; Kingsbury et. al., 2012:364). Furthermore, the whole experience of international patients and what they have gone through pre- and post-treatment periods and duration of medical treatment make them "vulnerable" both emotionally and physiologically (Ormond, 2015:4). Even so, it is not rare to come across utmost satisfactory results from the level of care quality in international patient services (Turner, 2015).

Despite the satisfaction from quality level of healthcare services, lack of cultural abilities among healthcare providers take its toll on the medical care which is rendered to international patients (Turner, 2015). To further complicating issue is that patients from abroad may have different cultural perception of health than medical service providers have, and this discrepancy needs to be considered and addressed within cross-cultural management (Mainil, 2012). In parallel, the importance of cultural awareness, cultural knowledge, intercultural skills, multicultural exposures, and cultural motivation in effectively working within the multicultural context of 
healthcare services need to be emphasized too (Campinha-Bacote, 2002). To take a step forward, "further professionalization" and cross-cultural training of healthcare providers were offered as a remedy for better interacting with patients from different cultures (Mainil, 2012; Turner, 2015). In the meantime, this would serve to improving the capacity of healthcare organization in providing safe, patient-centric, evidence-base, and accessible patient care (National Quality Forum (NQF), 2009).

These above conditions and factors in medical care of international patients from different cultures require a new skill set which allows healthcare workers efficiently deal with not only the patients and their caregivers but also among themselves (Clark \& Polesello, 2017; Fariselli et. al., 2008). More elaborately, this entails "deeper, internal individual understanding and skills set" among healthcare workforce (Clark and Polesello, 2017:337). In that way, it would be possible for employees, who are in charge of international patient services, to be able to understand and respond appropriately to the latent needs and expectations originated from "medical travelers' more inward-looking" psychological status throughout their experience of medical journey (Clark and Polesello, 2017; Ormond, 2015).

Based on this determination and understanding, having emotional and cultural intelligence are promising about creating the skills and accompanying behaviors among healthcare providers so that this way they can perform better in a challenging and more diverse work environment (Clark and Polesello, 2017; Fariselli et. al., 2008; Moss, 2004; Sharma, 2018). It was reported that proactive planning towards "international patient-friendly systems" should help reducing the "psychological stress" of healthcare staff originating from communicative and cultural issues with patients from abroad. Eventually, it was emphasized that the lesser the amount of stressor factors health workforce experience the higher the level of satisfaction of international patients would be (Endo et. al., 2015).

In that vein, based on a quantitative research among 68 midwives and obstetrician working in a large urban hospital, it was reported that having high emotional intelligence help work performance of healthcare staff to be higher, at the same time lessening the stress level being experienced. Based on the findings of this study, emotional intelligence is found to be “invaluable asset” for workforce in healthcare organizations (Fariselli et. al, 2008).

Hypothesis 1: $\mathrm{H} 1=$ There is a significant difference among private hospitals in terms of the overall score of emotional intelligence (EQ) of the participants. 
In another study, Güleryüz et. al. (2008) examined the relations among emotional intelligence, job satisfaction, and organizational commitment among nurses working in a teaching hospital. According to analysis of the collected 267 questionnaires, job satisfaction was found to have a mediator effect between emotional intelligence and organizational commitment. While "regulation of emotions" dimension of emotional intelligence has an indirect effect on organizational commitment through job satisfaction, emotional intelligence has direct effects on organizational commitment with its two dimensions of "self-emotional appraisal" and "use of emotion".

Hypothesis 2: $\mathrm{H} 2=$ There is a significant difference among private hospitals in terms of the dimensions of emotional intelligence of the participants, namely, evaluating own emotions, evaluating the emotions of others, using emotions of the self and, regulation of emotions.

In the study of McCallin \& Bamford (2007), the researchers looked into effect of emotional intelligence on the effectiveness of interdisciplinary work environment of healthcare organizations. Total of 44 health professional from seven different disciplines in two teaching hospital were interviewed for 80 hours. As the nature of their jobs require, team members had to work together continuously so that they were able to come up and catch up with the necessities. Among other things, the findings of this study suggested that while personality differences affect teamwork dearly, emotional intelligence as "the affective domain of interdisciplinary practice" is overlooked a lot when compared to technical knowhow and expertise. For that reason, selfawareness, self-management, social awareness, and social skills components of emotional intelligence were positioned at the center of effective teamwork as well as better outcomes of medical care.

On the other hand, there are different studies regarding to cultural competency and cultural intelligence in the literature (e.g. Aslan \& Kizir, 2019; Capell et. al., 2007; Chen et. al., 2012; Nafei, 2013). In the descriptive study by Nafei (2013), total of 280 physicians, nurses, administrative staff, and auditors working in 600 bed hospital, two groups of employees (physicians and nurses vs. administrative staff and auditors) are compared in terms of cultural intelligence and employee job satisfaction. There are total of 165 physicians and nurses vs. 115 administrative staff and auditors. The findings showed that there is a significant direct effect of metacognitive, cognitive, behavioral, and motivational aspects of cultural intelligence on employee job satisfaction. Furthermore, while openness to intercultural experiences was found to be related to four domains of cultural intelligence, it is also facilitating function over 
intercultural group performance.

Hypothesis 3: $\mathrm{H} 3=$ There is a significant difference among private hospitals in terms of the overall score of cultural intelligence (CQ) of the participants.

In another study, Aslan and Kizir (2019) examined the relationship between cultural sensitivity and cultural intelligence of nurses working in one training hospital. 144 nurses participated in this cross-sectional descriptive study. The findings reveal that relationship between average scores of cultural sensitivity and cultural intelligence were significant at moderate level among nurses. On the other hand, while cultural sensitivity scores of nurses were found to be high, their cultural intelligence scores were at moderate level. Furthermore, in order to provide health services at satisfactory level, it was recommended by researchers that awareness of cultural sensitivity and cultural intelligence should be increased among nurses by in-house trainings.

Hypothesis 4: H4= There is a significant difference among private hospitals in terms of the dimensions of cultural intelligence of the participants, namely, the cognitive, metacognitive, motivational and behavioral cultural intelligence.

Hence in the light of important findings of different studies, the study investigates difference among private hospitals in terms of emotional and cultural intelligences of their employees who are working in international patient services. It was hypothesized that there will be a significant difference among private hospitals in terms of emotional and cultural intelligences of their staff members.

\section{Method}

The aim of this cross-sectional study was to investigate whether there is any difference among private hospitals in terms of emotional intelligence and cultural intelligence of employees, who are working in international patient care. Hence, the emotional intelligence and cultural intelligence of the employees are dependent variables of the research, while different private hospitals are examined as independent variables.

\subsection{Participants and Setting}

Survey-based study was conducted on healthcare professionals, international patient coordinators and office workers, support services, and administrative staff who are working in private hospitals located in both Istanbul and Gebze, Turkey. Total of 776 employee were reached in this study. The criteria for inclusion in the study were having at least six months of work experience. Necessary permissions were obtained from a total of 7 private hospitals, 6 of which 
were in Istanbul ( 3 on the European side, 3 on the Anatolian side) and 1 in Gebze. $63.06 \%$ of the participants $(n=338)$ are private hospital employees with a bed capacity of 200 and above. The survey administration was carried out between 15 November 2018 and 14 June 2019.

\subsection{Instruments}

In order to determine the emotional intelligence and cultural intelligence of the employees, two questionnaires were used. Statements in both questionnaires were short and concise. Additionally, the criteria for validity and reliability evaluations were checked for both scales based on national and international literature.

Emotional Intelligence Scale (WLEIS) (Wong and Law, 2002) which consists of 16 expressions is the first questionnaire used in the present study. This scale has 4 factors; "Assessing Your Own Emotions (SEA)" 0.89 with cronbach alpha value; "Evaluating the Emotions of Others (OEA)" with 0.85 cronbach alpha value; "Use of Emotions (UOE)" with 0.88 cronbach alpha value; lastly, "Regulation of Emotions (ROE)" with 0.76 cronbach alpha value. Dirican (2013) adapted the scale to Turkish language. Cronbach alpha values for the four dimensions of SEA, OEA, UOE and ROE were 0.879, 0.851, 0.819, and 0.882 in Turkish version of the scale, respectively. When the explanatory variance values of the factors are examined; the first factor (SEA) explains $18.75 \%$ of the feature that is tried to be measured with this scale, the second factor (OEA) is its $18.7 \%$, the third factor (UOE) is $17.39 \%$ of it and, the fourth factor (ROE) is its $16.41 \%$. It was found that all four factors together explained $71.25 \%$ of it.

The second questionnaire which is used in this study is the Cultural Intelligence Scale (CQS C) developed by Van Dyne et al. (2008). It consists of 20 statements, which aims to evaluate the cultural intelligence levels of the participants. The cultural intelligence scale has four factors; "Metacognitive Cultural Intelligence (MCOG)" with 0.902 coefficient alpha, "Cognitive Cultural Intelligence (COG)" with 0.787 coefficient alpha, and "Motivational Cultural Intelligence (MOT)" with 0.868 coefficient alpha, and "Behavioral Cultural Intelligence (BEH)" with 0.911 coefficient alpha (Van Dyne et al., 2008). Aksoy (2013) adapted the original scale (CQS) into Turkish. Coefficient alphas of MCOG, COG, MOT and BEH for the Turkish version of the scale were $0,82,0,89,0,86$ and 0,90 , respectively. Based on the examination of the explanatory variance values of the factors are; the first factor (MCOG) explains $18.89 \%$, the second factor (COG) does $18.85 \%$, the third factor (MOT) does $16.81 \%$ and, the fourth factor (BEH) does $15.17 \%$. All together explained $69.72 \%$ of it. 
Participants were asked to rate the expressions in the emotional intelligence scale (WLEIS) and the Cultural Intelligence Scale (CQS (C) in Turkish using 5-point and 7-point Likert scale, respectively. Considering its higher response rates, mixed-mode surveys, combined of webbased and paper surveys were used for collecting data in this research (Greenlaw \& BrownWelty, 2009). The survey administration was carried out between 15 November 2018 and 14 June 2019.

\subsection{Equipment and Calculations}

Upon the approval of the ethics committee and obtaining necessary permissions from private hospitals, the surveys were first tested electronically using the web-based survey tool SurveyGizmo (SurveyGizmo, Boulder, USA) and made accessible to the employees of a private hospital between 15 November 2018 - 27 November 2018. Based on initially collected data during this testing period, there were only small changes made among demographic questions in the introduction part of the questionnaire.

\subsection{Data collection}

739 paper surveys were shared with the employees in the relevant sample group in seven private hospitals in Istanbul and Gebze. Paper survey administration was carried out by the researcher himself to the staff who volunteered to participate. In addition to the field study, web-based surveys were carried out by the researcher in the sample group between January 15, 2019 and June 14, 2019.

Total of 776 employees were reached in this research. Printed version of surveys were distributed to 739 of them. Remaining 37 of them accessed electronically. The participation rate to the study was $71 \%(\mathrm{n}=551)$ (Table 1$)$. Fifteen questionnaires were excluded from the study because of missing socio-demographic information and impartial completing $(n=536)$.

Table 1: Distribution Of Surveys Used In Analysis, By Hospital ( $\mathrm{n}=536)$

\begin{tabular}{lrrr}
\hline & Bed capacity & n* & \% \\
\hline Hospital A & 201 & 196 & $\mathbf{3 6 . 6 0}$ \\
\hline Hospital B & 219 & 134 & $\mathbf{2 5 . 0 0}$ \\
\hline Hospital C & 186 & 64 & $\mathbf{1 1 . 9 0}$ \\
\hline Hospital D & 160 & 44 & $\mathbf{8 . 2 0}$ \\
\hline Hospital E & 190 & 43 & $\mathbf{8 . 0 0}$ \\
\hline Hospital F & 170 & 37 & $\mathbf{6 . 9 0}$ \\
\hline Hospital G & 150 & 18 & $\mathbf{3 . 4 0}$ \\
\hline Total & 1276 & 536 & $\mathbf{1 0 0}$ \\
\hline
\end{tabular}

* Total of surveys collected $(n=536)$. 


\subsection{Ethical aspects of the study}

This study was administered upon permission of Ethics Committee of Marmara University Health Sciences Institute dated as 10.09.2018. After obtaining necessary permissions from the private hospitals where the study was going to be implemented, the researcher informed the managers of each hospital about the content and aim of the research. The researcher informed all participants in a one page "participant information sheet" where scope and purpose of study along with researcher's expectations from participants were shared. Additionally, written consent form was collected from the participants as a proof of personal approval in their participation to the study.

\subsection{Statistical analysis}

Non-parametric Kruskal Wallis variance analysis test was used in the analysis of possible differences between emotional intelligence and cultural intelligence (and sub-dimensions) of employees according to the institution they work in (Ery1lmaz \& Zengin, 2014; Field, 2013). IBM SPSS Statistics Version 22.00 (IBM Corp., Armonk, NY, USA) software was used for these analysis.

\section{Results}

The findings of the descriptive statistics based on demographic characteristics of the participants showed that more than three quarters of the participants $(78.0 \%)$ were female, $55.6 \%$ of them were single, $38.2 \%$ of them were at the age of 25 and below while $42.5 \%$ of them were holding Bachelor's degree, and 53\% of them are nurses (Table 2). Additionally, 25.9\% of participants $(n=139)$ reported that they were not healthcare staff.

Table 2: Demographic Characteristics of the Participants ( $N=536)$

\begin{tabular}{llrr}
\hline Demographic Characteristics & & $\mathrm{n}$ & $\%$ \\
\hline \multirow{2}{*}{ Gender } & Female & 418 & 78.0 \\
\cline { 2 - 4 } & Male & 118 & 22.0 \\
\hline \multirow{2}{*}{ Marital Status } & Married & 238 & 44.4 \\
\cline { 2 - 4 } & Single & 298 & 55.6 \\
\hline \multirow{4}{*}{ Age } & Below 26 & 205 & 38.2 \\
\cline { 2 - 4 } & $26-35$ & 174 & 32.5 \\
\cline { 2 - 4 } & $36-45$ & 109 & 20.3 \\
\cline { 2 - 4 } & $46-55$ & 34 & 6.3 \\
\cline { 2 - 4 } Education & Above 55 & 122 & 2.6 \\
\cline { 2 - 4 } & High School and lower & 22.7 \\
\cline { 2 - 4 } & Associate Diploma & 15.5 \\
\cline { 2 - 4 } & Bachelor's & 42.5 \\
\cline { 2 - 4 } & Master's & 19.3 \\
\hline
\end{tabular}




\begin{tabular}{llrr}
\hline & Physician & 42 & 7.8 \\
\cline { 2 - 4 } Purse & 284 & 53.0 \\
\cline { 2 - 4 } & Support Staff & 30 & 5.6 \\
\cline { 2 - 4 } & Int'l Patient Services Staff & 93 & 17.4 \\
\cline { 2 - 4 } & Admission Officer & 12 & 1.9 \\
\cline { 2 - 4 } & Manager & 39 & 7.3 \\
\cline { 2 - 4 } & Midwife \& Physiotherapist & 10 & 1.9 \\
\cline { 2 - 4 } & Health Technician & 26 & 4.9 \\
\hline
\end{tabular}

According to Kolmogorov Smirnov test and Shapiro Wilk test, the scale scores did not show a normal distribution according to the normal distribution examination. In testing the hypothesis of this research, it was examined first whether the scale scores show normal distribution or not. Based on Kolmogorov Smirnov and Shapiro Wilk tests' results, it was found that the scale scores were not normally distributed. Therefore, Kruskal Wallis test was used for the analysis.

As a result of testing Hypothesis 1 , it was found that there was no significant $(\mathrm{p}=0.284)$ difference among hospitals in terms of overall emotional intelligence (EQ) scores of participants (Table 3). Therefore, the first hypothesis (H1) of the study was not supported.

On the other hand, according to the testing results of Hypothesis 2, it was found that while there was no supportive evidence for any difference among private hospitals regarding to "assessing your own emotions" (SEA) ( $\mathrm{p}=0.559)$, “evaluating the emotions of others" (OEA) ( $\mathrm{p}=0.869)$, and "use of emotions" (UOE) (0.443) dimensions of emotional intelligence, moderately strong evidence for a significant difference was affirmed among private hospitals in terms of "regulation of emotions" (ROE) dimension at $p=0.024(\mathrm{p}<0.05)$ level. As a result of these results, the second hypothesis $(\mathrm{H} 2)$ was supported. 
Table 3: Statistical Evaluation Results of Emotional Intelligence and Its Dimensions -Based on Private Hospitals

\begin{tabular}{|c|c|c|c|c|c|c|c|}
\hline & Hospitals & $\mathbf{n}$ & Mean Rank & Mean & Chi-Square & df & $\mathbf{p}$ \\
\hline \multirow{7}{*}{ EQ } & Hospital A & 196 & 281.64 & 4.0651 & 7.421 & 6 & .284 \\
\hline & Hospital B & 134 & 246.55 & 3.9333 & & & \\
\hline & Hospital C & 64 & 268.19 & 3.9863 & & & \\
\hline & Hospital D & 44 & 251.84 & 3.9545 & & & \\
\hline & Hospital E & 43 & 293.45 & 4.0858 & & & \\
\hline & Hospital F & 37 & 288.20 & 4.0760 & & & \\
\hline & Hospital G & 18 & 230.56 & 3.8681 & & & \\
\hline \multirow{7}{*}{ SEA } & Hospital A & 196 & 282.25 & 4.3571 & 4.884 & 6 & .559 \\
\hline & Hospital B & 134 & 250.14 & 4.2052 & & & \\
\hline & Hospital C & 64 & 253.93 & 4.2188 & & & \\
\hline & Hospital D & 44 & 274.20 & 4.3182 & & & \\
\hline & Hospital E & 43 & 277.78 & 4.2907 & & & \\
\hline & Hospital F & 37 & 279.78 & 4.3581 & & & \\
\hline & Hospital G & 18 & 247.97 & 4.2500 & & & \\
\hline \multirow{7}{*}{ OEA } & Hospital A & 196 & 279.55 & 4.1033 & 2.495 & 6 & .869 \\
\hline & Hospital B & 134 & 255.18 & 3.9907 & & & \\
\hline & Hospital C & 64 & 273.63 & 3.9961 & & & \\
\hline & Hospital D & 44 & 267.51 & 4.0682 & & & \\
\hline & Hospital E & 43 & 265.94 & 4.0465 & & & \\
\hline & Hospital F & 37 & 263.27 & 4.0135 & & & \\
\hline & Hospital G & 18 & 248.42 & 3.9306 & & & \\
\hline \multirow{7}{*}{ UOE } & Hospital A & 196 & 280.88 & 4.0319 & 5.822 & 6 & .443 \\
\hline & Hospital B & 134 & 249.44 & 3.8825 & & & \\
\hline & Hospital C & 64 & 273.24 & 3.9805 & & & \\
\hline & Hospital D & 44 & 239.23 & 3.8580 & & & \\
\hline & Hospital E & 43 & 274.15 & 3.9767 & & & \\
\hline & Hospital F & 37 & 290.62 & 4.0743 & & & \\
\hline & Hospital G & 18 & 271.39 & 3.9861 & & & \\
\hline \multirow{7}{*}{ ROE } & Hospital A & 196 & 271.48 & 3.7679 & 14.605 & 6 & .024 \\
\hline & Hospital B & 134 & 253.55 & 3.6549 & & & \\
\hline & Hospital C & 64 & 275.81 & 3.7500 & & & \\
\hline & Hospital D & 44 & 245.02 & 3.5739 & & & \\
\hline & Hospital E & 43 & 329.85 & 4.0291 & & & \\
\hline & Hospital F & 37 & 288.53 & 3.8581 & & & \\
\hline & Hospital G & 18 & 191.00 & 3.3056 & & & \\
\hline
\end{tabular}

* $\mathrm{p}<0.05$ 
In the next step, pairwise comparisons of hospitals were performed in order to find where the corresponding differences are in terms of "regulation of emotions" scores of participants. As a result, only moderately significant difference $(\mathrm{p}=0.027<0.05)$ existed between participants

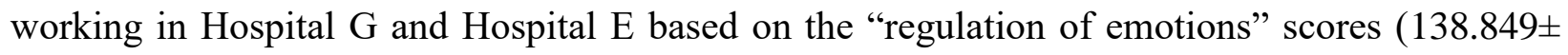
43.095) point of view (Table 4). Additionally, although it might be weak evidence, there might be marginally difference $(\mathrm{p}=0.096)$ between participants from Hospital B and Hospital $\mathrm{E}$ in terms of "regulation of emotions" scores $(-76.300 \pm 26.905)$ also.

Table 4: Pairwise Comparisons of Hospitals in Terms of "Emotion Regulation" Scores of Participants

\begin{tabular}{lrlrrr}
\hline Sample 1-Sample 2 & \multicolumn{1}{c}{ Test } & \multicolumn{1}{l}{ Std. } & \multicolumn{1}{l}{ Std. Test } & \multicolumn{1}{c}{$\mathrm{p}$} & \multicolumn{1}{c}{$\mathrm{p}^{*}$} \\
\hline Hospital G-Hospital D & 54.023 & 42.950 & 1.258 & .208 & 1.000 \\
Hospital G-Hospital B & 62.549 & 38.535 & 1.623 & .105 & 1.000 \\
Hospital G-Hospital A & 80.482 & 37.807 & 2.129 & .033 & .699 \\
Hospital G-Hospital C & 84.813 & 40.955 & 2.071 & .038 & .806 \\
Hospital G-Hospital F & -97.527 & 44.114 & -2.211 & .027 & .568 \\
Hospital G-Hospital E & 138.849 & 43.095 & 3.222 & .001 & $\mathbf{. 0 2 7} * *$ \\
Hospital D-Hospital B & 8.526 & 26.672 & .320 & .749 & 1.000 \\
Hospital D-Hospital A & 26.459 & 25.608 & 1.033 & .301 & 1.000 \\
Hospital D-Hospital C & 30.790 & 30.062 & 1.024 & .306 & 1.000 \\
Hospital D-Hospital F & -43.504 & 34.241 & -1.271 & .204 & 1.000 \\
Hospital D-Hospital E & 84.826 & 32.917 & 2.577 & .010 & .209 \\
Hospital B-Hospital A & 17.934 & 17.207 & 1.042 & .297 & 1.000 \\
Hospital B-Hospital C & -22.264 & 23.325 & -.955 & .340 & 1.000 \\
Hospital B-Hospital F & -34.979 & 28.508 & -1.227 & .220 & 1.000 \\
Hospital B-Hospital E & -76.300 & 26.905 & -2.836 & .005 & .096 \\
Hospital A-Hospital C & -4.330 & 22.100 & -.196 & .845 & 1.000 \\
Hospital A-Hospital F & -17.045 & 27.515 & -.619 & .536 & 1.000 \\
Hospital A-Hospital E & -58.367 & 25.850 & -2.258 & .024 & .503 \\
Hospital C-Hospital F & -12.715 & 31.703 & -.401 & .688 & 1.000 \\
Hospital C-Hospital E & 54.036 & 30.269 & 1.785 & .074 & 1.000 \\
Hospital F-Hospital E & 41.322 & 34.422 & 1.200 & .230 & 1.000 \\
\hline
\end{tabular}

$\mathrm{p}^{*}: \mathrm{p}$ value after Bonferroni correction

$* * \mathrm{p}<0.05$

According to the result of testing Hypothesis 3, it was revealed that there was no significant $(\mathrm{p}=0.108)$ difference among hospitals in terms of overall cultural intelligence (CQ) scores of participants (Table 5). Therefore, the third hypothesis (H3) of the study was not affirmed. Therefore, it was rejected.

Lastly, based on testing Hypothesis 4, the results showed that there was no supportive evidence for a difference among private hospitals in terms of scores of cultural intelligence aspects of participants (Table 5). However, there might be marginally difference $(\mathrm{p}=0.066)$ among private 
hospitals in terms of motivational dimension of cultural intelligence scores of participants. This could be interpreted as a weak evidence for difference among hospitals based on motivational cultural intelligence scores of participants (Carey et. al, 2015). For this reason, the last hypothesis (H4) could not be rejected.

Table 5: Statistical Evaluation Results of Cultural Intelligence and Its Dimensions -Based on Private Hospitals

\begin{tabular}{|c|c|c|c|c|c|c|c|}
\hline & Hospitals & $\mathbf{n}$ & Mean Rank & Mean & $\begin{array}{c}\text { Chi- } \\
\text { Square }\end{array}$ & df & $\mathbf{p}$ \\
\hline \multirow{7}{*}{ CQ } & Hospital A & 196 & 289.53 & 5.4089 & 10.415 & 6 & .108 \\
\hline & Hospital B & 134 & 239.84 & 5.1630 & & & \\
\hline & Hospital C & 64 & 274.34 & 5.3922 & & & \\
\hline & Hospital D & 44 & 254.22 & 5.2151 & & & \\
\hline & Hospital E & 43 & 266.02 & 5.2735 & & & \\
\hline & Hospital F & 37 & 250.81 & 5.1752 & & & \\
\hline & Hospital G & 18 & 309.33 & 5.4361 & & & \\
\hline \multirow{7}{*}{$\mathrm{MCOG}$} & Hospital A & 196 & 278.62 & 5.7298 & 2.389 & 6 & .881 \\
\hline & Hospital B & 134 & 262.41 & 5.5981 & & & \\
\hline & Hospital C & 64 & 274.10 & 5.6719 & & & \\
\hline & Hospital D & 44 & 262.30 & 5.5284 & & & \\
\hline & Hospital E & 43 & 265.37 & 5.6661 & & & \\
\hline & Hospital F & 37 & 242.59 & 5.5106 & & & \\
\hline & Hospital G & 18 & 259.58 & 5.5000 & & & \\
\hline \multirow{7}{*}{ COG } & Hospital A & 196 & 276.89 & 4.7851 & 5.854 & 6 & .440 \\
\hline & Hospital B & 134 & 252.38 & 4.6015 & & & \\
\hline & Hospital C & 64 & 294.90 & 5.0469 & & & \\
\hline & Hospital D & 44 & 246.98 & 4.6364 & & & \\
\hline & Hospital E & 43 & 263.49 & 4.7389 & & & \\
\hline & Hospital F & 37 & 253.35 & 4.6380 & & & \\
\hline & Hospital G & 18 & 299.08 & 4.8889 & & & \\
\hline \multirow{7}{*}{ MOT } & Hospital A & 196 & 291.50 & 5.6121 & 11.819 & 6 & .066 \\
\hline & Hospital B & 134 & 243.57 & 5.3170 & & & \\
\hline & Hospital C & 64 & 276.45 & 5.5688 & & & \\
\hline & Hospital D & 44 & 234.75 & 5.3091 & & & \\
\hline & Hospital E & 43 & 264.17 & 5.4298 & & & \\
\hline & Hospital F & 37 & 249.62 & 5.3158 & & & \\
\hline & Hospital G & 18 & 307.00 & 5.7444 & & & \\
\hline \multirow{7}{*}{ BEH } & Hospital A & 196 & 289.93 & 5.5086 & 9.431 & 6 & .151 \\
\hline & Hospital B & 134 & 244.38 & 5.1354 & & & \\
\hline & Hospital C & 64 & 255.65 & 5.2813 & & & \\
\hline & Hospital D & 44 & 272.76 & 5.3864 & & & \\
\hline & Hospital E & 43 & 250.05 & 5.2592 & & & \\
\hline & Hospital F & 37 & 261.68 & 5.2364 & & & \\
\hline & Hospital G & 18 & 308.08 & 5.6111 & & & \\
\hline
\end{tabular}




\section{Discussion}

This study sheds light on an examination of if there is any difference among private hospitals in terms of emotional intelligence and cultural intelligence of participants working in international patient services.

Regarding the first hypothesis of the study aiming to examine if there is any difference in terms of the overall score of emotional intelligence of the participants, Kruskal Wallis test scores show that there was no significant difference among private hospitals in that respect. The participants in this study frequently deal with people from different cultures during the diagnostic and treatment procedures of international patients. In that respect, this result is in parallel to the findings of Crowne (2013)'s research because she found that all forms of cultural exposure were not supposed to affect emotional intelligence. However, according to Bar-On, Brown, Kirkcaldy ve Thome (2000), different occupational cultures are one of the reasons for a difference in emotional intelligence among different workgroups. From that point of view, participants from each hospital may show some differences within themselves regarding the numbers of nonclinical staff and healthcare professionals in the international patient services and this may lead to a difference in emotional intelligence among hospitals. In that sense, finding no difference in overall score of emotional intelligence in this study contradicts with the findings of Bar-On et. al. (2000).

The results of testing the second hypothesis revealed that there was moderately strong difference among private hospitals regarding to emotion regulation aspect in emotional intelligence of employees who are dealing with international services within their organizations. When checked with the pairwise comparison in Kruskal Wallis test, both hospitals of which moderately strong difference was found out, have above 150 bed capacity. To give more detail, Hospital E which had higher score in emotion regulation has bigger capacity (190) than Hospital G has (150). This difference between two hospitals in terms of emotion regulation of participants might have been due to differences in work experience, age, marital status, or all (e.g. Boyatzis and Sala, 2004; Hur et. al, 2014; Khan and Minbashian, 2017; Mayer et. al., 2000; Pooja, and Kumar, 2016; Shipley et. al., 2010). According to further descriptive analysis on demographic information of the participants in these two hospitals, differences were found in experience levels, age, and marital status of participants. That the percentage of employees $(44,2 \%)$ having more experience (6 years and more ) in Hospital E was higher than the one (22\%) of Hospital G, participants working in Hospital E might have been more successful in regulation of emotions comparing to 
the ones in Hospital G. Furthermore, sample group of Hospital G were younger (26 years old and below) $(72,2 \%)$ members than the ones $(44,3 \%)$ of Hospital E. In that sense, it could be projected that Hospital E employees might have been regulating their and others' emotions better than Hospital G employees. Additionally, the ones reported their marital status as single were higher $(88,9 \%)$ in Hospital $\mathrm{G}$ than Hospital E $(65,1 \%)$. It could be assumed that married people might have showed better performance in regulation of emotions comparing to singles. Otherwise, in terms of other demographic parameters, such as ratios of gender, nurse, and education level, both hospitals were similar.

Further comments could be also made about emotion regulation in terms of being only aspect of difference in emotional intelligence among hospitals as a result of testing the second hypothesis. Regulation of emotion was considered as critical ability which helps optimizing functions of healthcare worker via better management of their both positive and negative responses when dealing with patients, caregivers as well as coworkers (Gross, 1998; Vandewaa et. al, 2016). Therefore, this finding is unique contribution to the literature in both emotional intelligence and international patient services in healthcare.

The third hypothesis of the present study was about examining a difference among private hospitals in terms of the overall score of cultural intelligence of hospital workers. Similar to the results of the first hypothesis, there was no strong evidence towards a significant difference among the hospitals. As the volumes of international patients in each hospital and in proportion to that, cultural exposure of each hospital's workers was not the same, this result was not expected by the researcher. In that vein, Crowne (2013) found in her research that all forms of cultural exposure had an impact on cultural intelligence. However, the findings of the same study revealed also that cultural exposure had no effect on emotional intelligence, which is relevant to one of the results in this current study.

In the last hypothesis, difference among private hospitals was examined in terms of the dimensions of cultural intelligence of the participants, namely, the cognitive, metacognitive, motivational and behavioral cultural intelligence. The testing results of the fourth hypothesis showed that there was no significant difference among hospitals regarding four aspects of cultural intelligence, namely, the cognitive, metacognitive, motivational and behavioral cultural intelligence. On the other hand, it was found that, even though in marginal level, there was some differences among hospitals in terms of the motivational aspect of cultural intelligence. Related to motivational cultural intelligence, the research performed by Chen et. al. (2012) revealed that 
high firm motivational CQ showed better cross-cultural interpersonal interactions either among coworkers or between manager and employee. In that regard, marginal difference among hospitals might have indicated that some hospitals are performing better in cross-cultural interactions, in other words, satisfactory services to international services.

In terms of limitations of this study, using self-report measures, which are common in social sciences, for evaluating both emotional intelligence and cultural intelligence of participants could be counted as one of them. Actual and perceived performance level difference and either good or bad exaggeration tendency are some of the common issues related to self-report instruments in the literature (Ciarriochi et al., 2000; Crowne, 2013; Goldenberg et al., 2006; Libbrecht et. al., 2010).

Other limitations in this present study may be due to differences in understanding of the items in each questionnaires and different cultures of participants (Triandis, 2004). 7,1\% of the participants $(n=38)$ in the present study reported that their mother tongues are different than Turkish.

Despite majority of international patients prefer private hospitals for their health problems, the results of this research are not generalizable for all hospital types because of including only private hospitals.

\section{Conclusion}

Considering almost $26 \%$ of participants being non-clinical hospital staff in this study, relatively heterogenous workforce was noticed throughout the services of international patients comparing to more homogenous structure of healthcare workers otherwise.

The findings of this study revealed that hospitals were not different from each other in terms of the overall score of emotional intelligence of their employees who have different roles and responsibilities in addressing the needs and expectations of international patients during their treatment in the hospital. Furthermore, emotion regulation aspect was found as moderately significant differentiator among private hospitals among other domains of emotional intelligence in international patient care.

On the other hand, private hospitals are not significantly different from each other in terms of any aspects of cultural intelligence of employees who are providing services to patients from abroad. However, there may be a weak evidence in favor of a difference among private hospitals 
in terms of motivational cultural intelligence of employees who are dealing with international patients in the hospital.

Overall, this study is unique in terms of highlighting some differences among private hospitals in terms of emotional intelligence and cultural intelligence in their services towards patients who traveled from their home country for health reasons.

\section{Recommendations}

The findings of this study are important in terms of attracting attentions of researchers into the multicultural, multi-professional and dynamic structure of medical care services of international patients in hospitals. Because of the importance of satisfactory results from international patient services, both emotional and cultural intelligence should be improved through inhouse trainings and using other means especially in medical care of international patients. In that vein, to see the effect of trainings in both emotional intelligence and cultural intelligence, it is recommended to repeat the same study on the same sample group and settings after trainings. Additionally, it could also be investigated the role of upper management, demographic parameters, international work experience towards better international patient services in the hospitals. Another study could be performed in public hospitals and see if there are any differences between public and private hospitals in this regard.

\section{Acknowledgement}

The author would like to thank Humeyra Genc for her valuable support and contribution. The author expresses his deep appreciation to all participants and healthcare managers of the hospitals for their time and assistance in this study.

\section{References}

Aksoy, Z. (2003). Kültürel Zeka ve Çokkültürlü Ortamlardaki Rolü (Doctoral dissertation) Ege Üniversitesi Sosyal Bilimler Enstitüsü, İzmir.

Ang, S., Van Dyne, L., Koh, C., Ng, K. Y., Templer, K. J., Tay, C., \& Chandrasekar, N. A. (2007). Cultural intelligence: Its measurement and effects on cultural judgment and decision making, cultural adaptation and task performance. Management and organization review, 3(3), 335-371.

Aslan, S., \& Kizir, Z. (2019). Bir Hastanede Çalışan Hemşirelerin Kültürel Duyarlılıkları ile Kültürel Zekaları Arasındaki İlişkinin İncelenmesi. Celal Bayar Üniversitesi Sağlık Bilimleri Enstitüsü Dergisi, 6(2), 115-120.

Aronson, J., Burgess, D., Phelan, S. M., \& Juarez, L. (2013). Unhealthy interactions: The role of stereotype threat in health disparities. American journal of public health, 103(1), 50-56. 
Bar-On, R., Brown, J. M., Kirkcaldy, B. D., \& Thome, E. P. (2000). Emotional expression and implications for occupational stress; an application of the Emotional Quotient Inventory (EQi). Personality and individual differences, 28(6), 1107-1118.

Boyatzis, R.E. \& Sala, F. (2004). The Emotional Competency Inventory (ECI). In Glenn Geher (ed.): Measuring emotional intelligence: common ground and controversy. Hauppauge, NY: Nova Science Publishers.

Büyüköztürk, Ş. (2018). Sosyal bilimler için veri analizi el kitabı. Pegem Atıf İndeksi, 001-214.

Campinha-Bacote, J. (1999). A model and instrument for addressing cultural competence in health care. Journal of Nursing education, 38(5), 203-207.

Campinha-Bacote, J. (2002). The process of cultural competence in the delivery of healthcare services: A model of care. Journal of transcultural nursing, 13(3), 181-184.

Capell, J., Veenstra, G., \& Dean, E. (2007). Cultural Competence in Healthcare: Critical Analysis of the Construct, Its Assessment and Implications. Journal of Theory Construction \& Testing, 11(1).

Carey, D., Rosen, S., Krishnan, S., Pearce, M. T., Shepherd, A., Aydelott, J., \& Dick, F. (2015). Generality and specificity in the effects of musical expertise on perception and cognition. Cognition, 137, 81-105.

Casey, V., Crooks, V. A., Snyder, J., \& Turner, L. (2013). "You're dealing with an emotionally charged individual...": an industry perspective on the challenges posed by medical tourists' informal caregiver-companions. Globalization and health, 9(1), 31.

Chen, X. P., Liu, D., \& Portnoy, R. (2012). A multilevel investigation of motivational cultural intelligence, organizational diversity climate, and cultural sales: Evidence from US real estate firms. Journal of applied psychology, 97(1), 93.

Ciarrochi, J. V., Chan, A. Y., \& Caputi, P. (2000). A critical evaluation of the emotional intelligence construct. Personality and Individual differences, 28(3), 539-561.

Clark, J. M., \& Polesello, D. (2017). Emotional and cultural intelligence in diverse workplaces: Getting out of the box. Industrial and Commercial Training.

Connell, J. (2006). Medical tourism: Sea, sun, sand and... surgery. Tourism management, 27(6), 1093-1100.

Connell, J. (2013). Contemporary medical tourism: Conceptualisation, culture and commodification. Tourism management, $34,1-13$.

Crowne, K. A. (2013). Cultural exposure, emotional intelligence, and cultural intelligence: An exploratory study. International Journal of Cross Cultural Management, 13(1), 5-22.

Dirican, A. H. (2013). Duygusal zekanın örgütsel vatandaşlık davranışı ve üretkenlik karşıtı davranışlar üzerine etkisi. Gebze Technical University Social Science Institute. Unpublished master's thesis. Gebze.

Dreachslin, J. L., Hunt, P. L., \& Sprainer, E. (2000). Workforce diversity: implications for the effectiveness of health care delivery teams. Social science \& medicine, 50(10), 1403-1414.

Endo, H., Okamura, S., \& Toya, M. (2015). The national context of medical travel within Japan. In Handbook on Medical Tourism and Patient Mobility. Edward Elgar Publishing. 
Erylmaz, B., \& Zengin, B. (2014). Sosyal medyada konaklama işletmelerine yönelik tüketici yaklaşımları üzerine bir araştırma. İşletme Bilimi Dergisi, 2(1), 147-167.

Fariselli, L., Freedman, J., Ghini, M., \& Valentini, F. (2008). Stress, emotional intelligence, and performance in healthcare. Retrieved December, 2, 2009.

Field, A. (2013). Discovering statistics using IBM SPSS statistics. sage.

George, B.P., Henthorne, T.L. and Williams, A.J. (2010) 'Determinants of satisfaction and dissatisfaction among preventive and curative medical tourists: a comparative analysis', Int. J. Behavioural and Healthcare Research, Vol. 2, No. 1, pp.5-19.

Goldenberg, I., Matheson, K., \& Mantler, J. (2006). The assessment of emotional intelligence: A comparison of performance-based and self-report methodologies. Journal of personality assessment, 86(1), 33-45.

Gould L.J. (1993) Contemporary perspectives on personal and organisational authority: the self in a system of work relationships. In The Psychodynamics of Organisations (L. Hirschhorn \& C.K. Barnett eds), pp. 49-63. Temple University Press, Philadelphia.

Greenlaw, C., \& Brown-Welty, S. (2009). A comparison of web-based and paper-based survey methods: testing assumptions of survey mode and response cost. Evaluation review, 33(5), 464480 .

Gross, J. J. (1998). The emerging field of emotion regulation: An integrative review. Review of general psychology, 2(3), 271-299.

Güleryüz, G., Güney, S., Aydın, E. M., \& Aşan, Ö. (2008). The mediating effect of job satisfaction between emotional intelligence and organisational commitment of nurses: A questionnaire survey. International journal of nursing studies, 45(11), 1625-1635.

Hur, W. M., Moon, T. W., \& Han, S. J. (2014). The role of chronological age and work experience on emotional labor. Career Development International.

Khan, M., \& Minbashian, A. (2017). The Effect of Age and Work Experience on Emotional Intelligence: A Meta-Analytic Review. In Academy of Management Proceedings (Vol. 2017, No. 1, p. 15324). Briarcliff Manor, NY 10510: Academy of Management.

Kingsbury, P., Crooks, V. A., Snyder, J., Johnston, R., \& Adams, K. (2012). Narratives of emotion and anxiety in medical tourism: on State of the Heart and Larry's Kidney. Social \& Cultural Geography, 13(4), 361-378.

Kleefield, S. (2016). Choosing the good hospital: helping medical tourists make informed decisions. Smith MK, Puczkó L, editors. In the Routledge Handbook of Health Tourism. Routledge. 259-273.

Libbrecht, N., Lievens, F., \& Schollaert, E. (2010). Measurement equivalence of the Wong and Law Emotional Intelligence Scale across self and other ratings. Educational and Psychological Measurement, 70(6), 1007-1020.

Lipsitz, L. A. (2012). Understanding health care as a complex system: the foundation for unintended consequences. Jama, 308(3), 243-244.

Liu, I. C., \& Chen, C. C. (2013). Cultural issues in medical tourism. American Journal of Tourism Research, 2(1), 78-83.

Mainil, T. (2012). Transnational health care and medical tourism: understanding 21st-century patient mobility. NRIT Media, Netherlands. 
Mainil, T. J. G. M. J., Platenkamp, V. C. J. M., \& Meulemans, H. (2010). Diving into the contexts of in-between worlds: worldmaking in medical tourism. Tourism analysis, 15(6), 743754.

Mayer, J.D., Salovey, P., \& Caruso, D. (2000). Models of emotional intelligence. In R.J. Sternberg (ed.): Handbook of intelligence. Cambridge, UK: Cambridge University Press.

McCallin, A., \& Bamford, A. (2007). Interdisciplinary teamwork: is the influence of emotional intelligence fully appreciated?. Journal of nursing management, 15(4), 386-391.

Mitas, O., Nawijn, J., \& Jongsma, B. (2016). Between tourists. Smith MK, Puczkó L, editors. In the Routledge Handbook of Health Tourism. Routledge. 47-64.

Moss, M. T. (2004). The emotionally intelligent nurse leader (Vol. 20). John Wiley \& Sons.

Nafei, W. A. (2013). The impact of cultural intelligence on employee job performance: an empirical study on King Abdel-Aziz Hospital in Al-Taif Governorate, Kingdom of Saudi Arabia. International Journal of Business and Management, 8(1), 26.

National Quality Forum (NQF) (2009). A comprehensive framework and preferred practices for measuring and reporting cutural competency: A consensus report. Washington, DC: National Quality Forum.

Ogbolu, Y., Scrandis, D. A., \& Fitzpatrick, G. (2018). Barriers and facilitators of care for diverse patients: Nurse leader perspectives and nurse manager implications. Journal of nursing management, 26(1), 3-10.

Ormond, M. (2016). Knowledge transfer in the medical tourism industry: The role of transnational migrant patients and health workers.

Ormond, M. (2015). Solidarity by demand? Exit and voice in international medical travel - The case of Indonesia. Social Science and Medicine, 124, 305-312.

Piacentini, T., O’Donnell, C., Phipps, A., Jackson, I., \& Stack, N. (2019). Moving beyond the 'language problem': developing an understanding of the intersections of health, language and immigration status in interpreter-mediated health encounters. Language and Intercultural Communication, 19(3), 256-271.

Pooja, P., \& Kumar, P. (2016). Demographic variables and its effect on emotional intelligence: A study on Indian service sector employees. Annals of neurosciences, 23(1), 18-24.

Priebe, S., Sandhu, S., Dias, S., Gaddini, A., Greacen, T., Ioannidis, E., ... \& Riera, R. P. (2011). Good practice in health care for migrants: views and experiences of care professionals in 16 European countries. BMC public health, 11(1), 187.

Ratnapalan, S., \& Uleryk, E. (2014). Organizational learning in health care organizations. Systems, 2(1), 24-33.

Seeleman, C., Essink-Bot, M. L., Stronks, K., \& Ingleby, D. (2015). How should health service organizations respond to diversity? A content analysis of six approaches. BMC health services research, 15(1), 510.

Sharma, P. (2018). Intercultural service encounters: Cross-cultural interactions and service quality. Palgrave MacMillan.

Shipley, N. L., Jackson, M. J., \& Segrest, S. (2010). The effects of emotional intelligence, age, work experience, and academic performance. 
Taylor, R. (2005). Addressing barriers to cultural competence. Journal for Nurses in Professional Development, 21(4), 135-142.

Thomas, D. C. (2006). Domain and development of cultural intelligence: The importance of mindfulness. Group \& Organization Management, 31(1), 78-99.

Thøgersen, J., Juhl, H. J., \& Poulsen, C. S. (2009). Complaining: A function of attitude, personality, and situation. Psychology \& Marketing, 26(8), 760-777.

Triandis HC. (2004) Culture and social behavior. McGraw-Hill Company Custom Publishing; US.

Turner, L. L. (2015). Lived Experiences of Service Members' Medical Care Rendered by Culturally Different Caregivers (Doctoral dissertation, The University of the Rockies)

Vandewaa, E. A., Turnipseed, D. L., \& Cain, G. (2016). Panacea or placebo? An evaluation of the value of emotional intelligence in healthcare workers. Journal of health and human services administration, 438-477.

Van Dyne, L., Ang, S., \& Koh, C. (2008). Development and validation of the CQS: The cultural intelligence scale. In: Ang S, Van Dyne L, editors. Handbook of Cultural Intelligence: Theory, Measurement, and Applications. M.E. Sharpe Inc.; New York.16-38.

Van Dyne, L., Ang, S., Ng, K. Y., Rockstuhl, T., Tan, M. L., \& Koh, C. (2012). Sub-dimensions of the four-factor model of cultural intelligence: Expanding the conceptualization and measurement of cultural intelligence. Social and personality psychology compass, 6(4), 295-313.

Ward, C., Fischer, R., Zaid Lam, F. S., \& Hall, L. (2009). The convergent, discriminant, and incremental validity of scores on a self-report measure of cultural intelligence. Educational and Psychological Measurement, 69(1), 85-105.

Wong, C. S., \& Law, K. S. (2002). The effects of leader and follower emotional intelligence on performance and attitude: An exploratory study. The leadership quarterly, 13(3), 243-274 